\title{
LETTERS
}

\section{Sensible approaches to manage the current opioid crisis}

The current opioid crisis is a complex health care issue and a clinical guideline ${ }^{1}$ alone will not resolve the issue. There is an urgent need for a sensible overall approach to this problem. Our suggestions:

1. Ads for prescription narcotics in reputable medical journals need to be stopped immediately.

2. A highly publicized media campaign should be developed that highlights the insuffficient evidence for the benefits of opioids for long-term use. (We should target both physicians and the patient community here.)

3. Physicians who prescribe opioids responsibly may expect to receive bad reviews from some patients. We need to develop tools for physicians to help them manage their online reputation, despite unfair reviews of their responsible behaviour.

4. Development of an online education course to help physicians improve their communication skills (e.g., how to say no without upsetting the patient and, more importantly, without harming the physician-patient relationship). In addition, this proposed course needs to show physicians how to manage their busy daily schedule and how to allocate reasonable time for explaining the known short- and long-term adverse effects and highly addictive properties of opioids to patients.

5. It is time that physicians learn about promising alternative therapies for pain management. It is time to address pain management with a collaborative team approach: emergency department and family physi- cians need to have access to an effective platform that facilitates frequent, open and regular conversation with pain specialists, physical therapists, chiropractors, acupuncturists, massage therapists, mental health providers and addiction specialists. If this is feasible, it won't be impossible to find the best solution for the opioid crisis in Canada.

6. The current health insurance system is also part of the problem, and we need to think seriously and bring sensible changes to coverage, including extended coverage for promising alternative therapies for pain management.

7. Current weak and ineffective approaches for the control of illegal drugs need to be addressed sensibly.

\section{Ediriweera Desapriya PhD}

Research Associate, Department of Emergency Medicine, Faculty of Medicine, The University of British Columbia, Vancouver, BC

\section{Kavi Ratnaweera BMLSC}

Research Assistant, Department of Emergency Medicine, Faculty of Medicine, The University of British Columbia, Vancouver, BC

- Cite as: CMAJ 2017 September 18;189: E1197. doi: 10.1503/cmaj.733161

\section{References}

1. Busse JW, Craigie S, Juurlink DN, et al. Guideline for opioid therapy and chronic noncancer pain. CMAJ 2017;189:E659-66.

\section{Competing interests: None declared.}

Funding: The Canadian Executive Council on Addictions funded the project entitled "Cross-country scan of existing programs and tools for raising awareness about addiction and substance use in emergency care settings - 2017." This letter was developed as part of this project. 